Research Article

\title{
Investigation into the Application of Construction and Demolition Waste in Urban Roads
}

\author{
Youyun Li, Hui Zhou, Linjian Su, Hang Hou, and Li Dang \\ School of Highway, Chang'an University, Xi'an 710064, China \\ Correspondence should be addressed to Hui Zhou; 571493995@qq.com
}

Received 12 April 2017; Revised 10 August 2017; Accepted 3 October 2017; Published 5 December 2017

Academic Editor: Meor Othman Hamzah

Copyright ( $) 2017$ Youyun Li et al. This is an open access article distributed under the Creative Commons Attribution License, which permits unrestricted use, distribution, and reproduction in any medium, provided the original work is properly cited.

\begin{abstract}
The recycling and reuse of waste materials is a topic of global concern and great international interest for those interested in sustainable development and protecting the environment. In recent decades, global production of construction and demolition waste (C\&D waste) has significantly increased and became a worldwide problem. This research proposes to evaluate the feasibility of using aggregate from recycled C\&D waste for urban road embankment applications based on the Sanhuan road construction project in eastern Xi'an. An extensive suite of laboratory and field compaction tests were carried out to determine the physical properties and engineering characteristics of the C\&D waste. The effect of curing on the strength of the C\&D waste was investigated using unconfined compression strength (UCS), California bearing ratio (CBR), and deflection tests. The results show that the $C \& D$ waste has the characteristics of high strength and significant stability after simple treatment and further suggest that the use of these materials for paving urban road embankments is feasible. This study is of value for the reasonable and effective promotion of using C\&D waste recycled materials in road subgrade applications.
\end{abstract}

\section{Introduction}

With the rapid development of the construction industry and the accelerated pace of urbanization, large numbers of old buildings are being demolished in urban areas, resulting in extremely significant amounts of C\&D waste. The amount of C\&D waste in China has accounted for as much as $30 \%-40 \%$ of total annual urban solid waste. Specifically, the demolition of $1 \mathrm{~m}^{2}$ buildings results in $0.5-1.0 \mathrm{~m}^{3}$ of $C \& D$ waste, and every 10 thousand $\mathrm{m}^{2}$ construction process will produce 500-600 tons of C\&D waste [1]. The average annual generation of C\&D waste in China was approximately 2.36 billion tons during the period from 2003 to 2013 [2]. C\&D waste is mainly composed of metal, concrete, mortars, bricks, woods, and plastic. Theoretically, by comparison with other kinds of urban garbage, C\&D waste has high potential for having recycling and economic value, $80 \%$ of which may be reused [3-5]. However, to date, most of the C\&D waste produced in China has been disposed by simple landfilling or dumping, which in turn creates a potential risk that threatens the security of the ecology and sustainable development in the region [6-9]. As shown in Figure 1, the recycling rate in China was merely $9.5 \%$ in 2012, which was lower than the recycling rate of most EU countries [2].

The recycling and reuse of waste materials, such as $C \& D$ waste, waste plastics and rubber, tailing, and ladle furnace slag, has been carefully studied in the last few decades in a number of countries around the world, and techniques have been proposed for how to successfully use these materials in pavements or subgrades [10-19]. Research on recycled aggregates of C\&D waste has mainly reflected its basic performance in road base or subbase applications. For instance, for cement concrete pavement, Ekanayake and Ofori [20] reported that, in the United States, more than 20 individual states use C\&D waste in highway construction. Sobhan and Krizek [21] investigated the flexural fatigue behavior of a stabilized fiber-reinforced pavement base course material that was composed largely of C\&D waste with small amounts of Portland cement and fly ash; this study found that the performance of the composite material was satisfactory as a base material. Park [22] observed that the compaction degree of different sizes, dissimilar kinds of gradation, and different kinds of mixtures of recycled aggregate have a significant impact on the bond strength and 


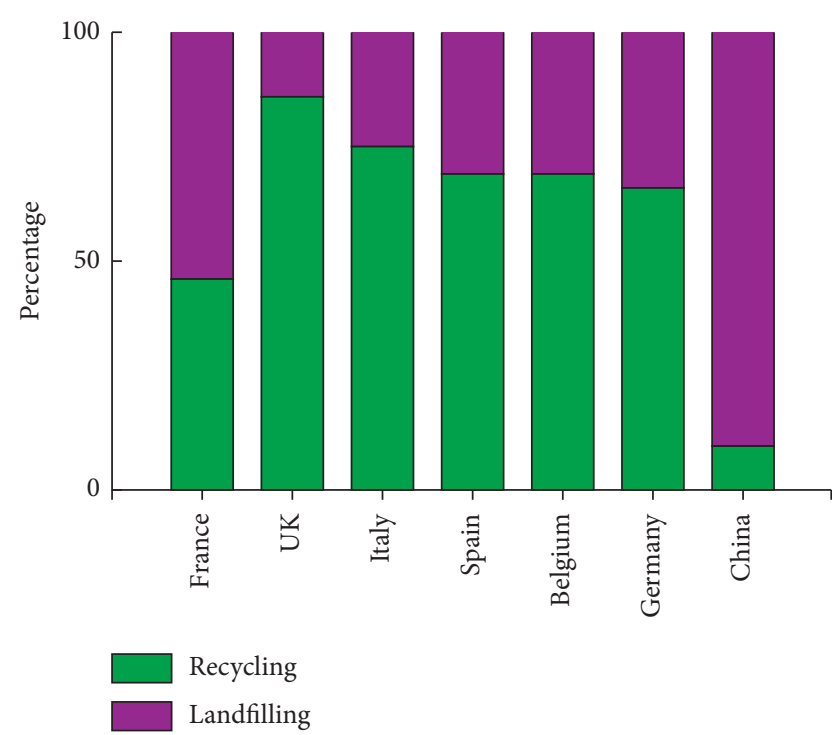

FIgURE 1: Treatment of China's C\&D waste with other countries (in 2012) [2].

resilient modulus of the road base. Chi and Chan [23] performed a series of shear strength and UCS tests based on adjusting the moisture content and particle gradation of C\&D waste and found that it is feasible to apply these materials in concrete pavement bases/subbases. Ayan et al. [24] noted that the optimal moisture content of recycled C\&D waste used as a subbase material was higher than that of natural aggregates. Xuan et al. [25] evaluated the unconfined compressive strength, static elastic modulus, and indirect tensile strength of cement-treated C\&D waste aggregates and concluded that this material has positive mechanical properties when used as a road base layer. Parallel to this, other authors have focused on assessing the feasibility of using C\&D waste aggregates as subbase and base layers for asphalt concrete [26-31].

The majority of previous studies have used laboratory tests to analyze the physical and mechanical properties of C\&D waste, and they demonstrate its feasibility as a road base or subbase. To date, nevertheless, there are few studies on C\&D waste used as an urban road embankment material [32-34]. Additionally, the mechanical properties and engineering characteristics of the C\&D waste in different areas are different, and it remains to be verified by means of field compaction tests whether laboratory tests can be used to guide field construction. In this study, based on the Sanhuan road project in eastern Xi'an, we conduct an extensive suite of laboratory and field compaction tests to thoroughly evaluate the engineering properties and extensive applications of C\&D waste as an urban road embankment material.

\section{Project Profile}

The Xi'an Sanhuan road project, with a total length of $71.4 \mathrm{~km}$, is one of the highest grade urban road projects in China. The east Sanhuan road runs north to the high-speed Xie Wang Interchange and south to Nandian Village. It is
$14.7 \mathrm{~km}$ long and is designed for two-way traffic, with eight lanes in each direction. After the project is completed, the east Sanhuan road will be connected to the Xi-Tong, Xi-Yan expressway, and many other highways, and it will serve as an important channel to enter and exit the city and to carry heavy highway traffic (Figure 2).

The C\&D waste investigated in this study came from a residential demolition site located near the midpoint of the east Sanhaun road, Xi'an. The amount of C\&D waste was estimated initially at approximately 300 thousand cubic meters and involving a length of about 700 meters. The average thickness of the $C \& D$ waste on the surface was approximately 3.0 meters after the demolition, as shown in Figure 3. The road in the waste disposal area was designed as an embankment structure with a filling height of 2.5-4 meters, according to the design requirements of the construction drawing. In order to reduce environmental pollution and reduce project cost, the $\mathrm{C} \& \mathrm{D}$ waste as an embankment filler was fully utilized in this project.

\section{Laboratory Test}

3.1. Sieving Test. The particle composition of the mixture has an important influence on its physical and mechanical properties [35-38]. Therefore, before running compaction tests, we analyzed the composition of the sample, and the screening results are shown in Figure 4. If the ratio of fine (passing a $4.75 \mathrm{~mm}$ sieve) to coarse (retained by a $4.75 \mathrm{~mm}$ sieve) material is defined as $K_{w}$ [39-41], $K_{w}$ of the C\&D waste was approximately 0.35 before the compaction, indicating that the small and medium size composition of $C \& D$ waste was less. Therefore, the porosity and permeability coefficient were relatively large, and it was easy to produce significant settlement deformation under the external load conditions for a long period of time. In terms of the theoretical analysis, the composition of the fine material should be 1-2 times of that of the coarse material, and the road effect can reach a better state [42].

3.2. Compaction Test. In laboratory compaction tests, the selection of the test parameters was carried out in strict accordance with the parameters determined by the test method of soils for highway engineering (JTG E40-2007) [43] (Table 1). At the same time, in order to reflect the status of the filler more truly, the samples were selected from three different locations (JZ-1, JZ-2, and JZ-3) at the construction site. The relationship between the moisture content and the dry density of the C\&D waste and the grain size distribution is shown in Figures 5 and 6.

We determined that the maximum dry density difference among the $C \& D$ waste from three construction sites was not more than $5 \%$, and the optimum moisture content varied between 15 and $16 \%$. Hence, a single index may be utilized for compaction control in embankment construction. Additionally, the particle content of the three sites was different, but the overall percentage of its mass content was almost the same. The particle composition of the C\&D waste from the different sites was basically uniform; the material 


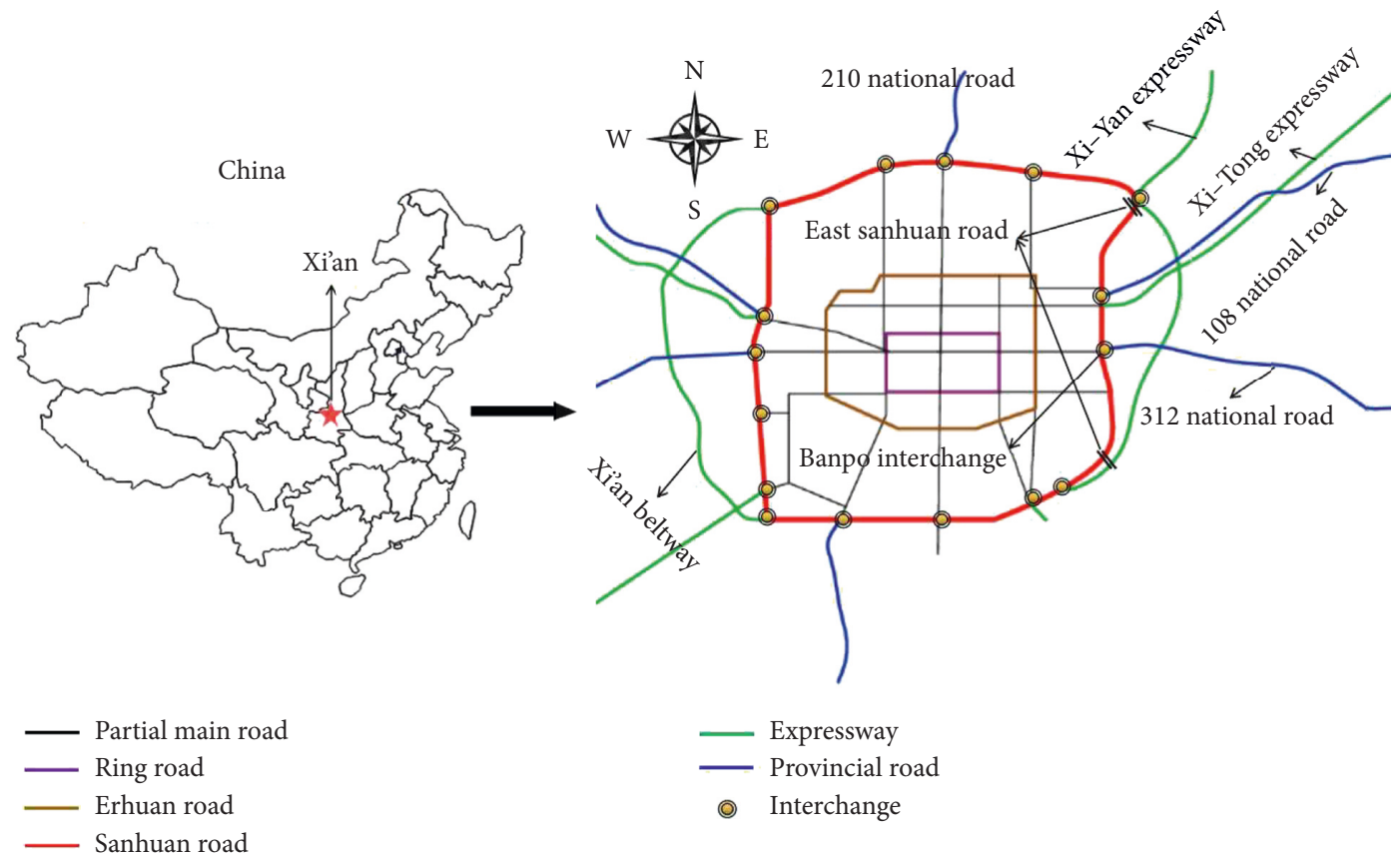

Figure 2: Schematic diagram of the east Sanhuan road in Xi'an.

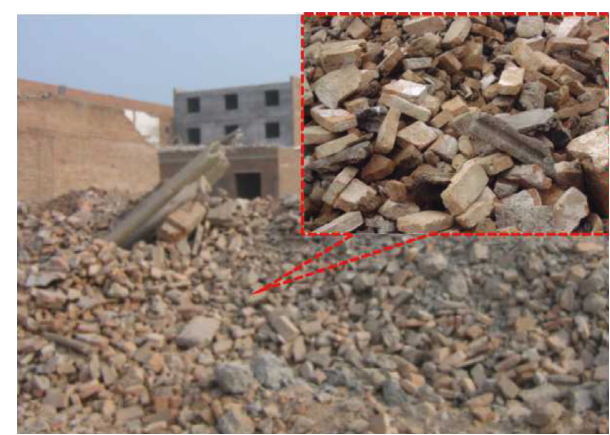

Figure 3: Residential demolition site.

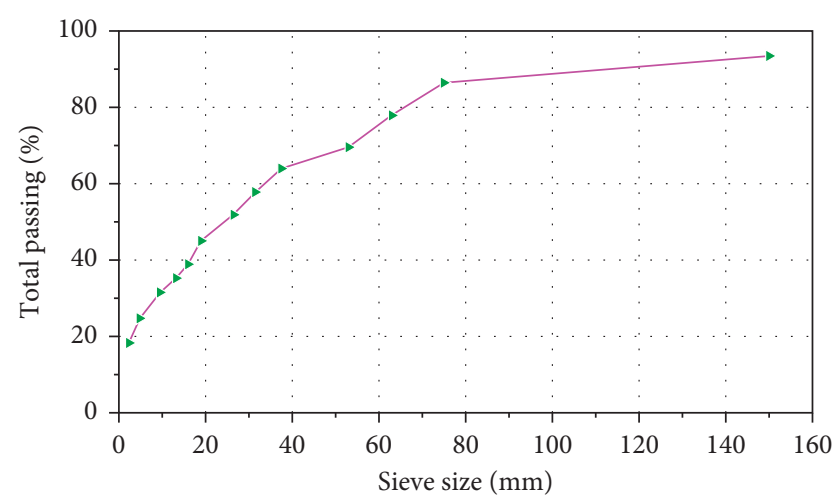

Figure 4: Gradation curve of C\&D waste sample.

with a particle size of less than $1 \mathrm{~mm}$ accounted for $40 \%$ of the total mass, and particles sized $2-3 \mathrm{~mm}$ accounted for approximately $38 \%$. After the compaction of the $C \& D$ waste, the ratio of fine to coarse material increased to 1.0 , which
Table 1: Technical parameters of compaction test [43].

\begin{tabular}{lccc}
\hline $\begin{array}{l}\text { Hammer } \\
\text { weight }(\mathrm{kg})\end{array}$ & $\begin{array}{c}\text { Falling } \\
\text { distance }(\mathrm{cm})\end{array}$ & $\begin{array}{c}\text { Compaction } \\
\text { layer }\end{array}$ & $\begin{array}{c}\text { Compaction } \\
\text { times }\end{array}$ \\
\hline 4.5 & 45 & 3 & 98 \\
\hline
\end{tabular}

indicates that the content of fine material in the C\&D waste greatly increased, and the road performance of the filling material has been substantially improved.

3.3. UCS Test. In order to analyze the overall stability of the embankment after the field compaction of the C\&D waste for use as a filler, the UCS test was conducted. A total of six specimens were selected for this test, and the size of each specimen was $\Phi 150 \mathrm{~mm} \times 150 \mathrm{~mm}$. When the test was carried out, the moisture content of the filler was controlled for optimal moisture content (15.5\%). Subsequently, the model was placed on the shaking table for vibration compaction, so that the maximum dry density was consistent with the maximum dry density (approximately $1.81 \mathrm{~g} / \mathrm{cm}^{3}$ ) after field rolling. The compaction degree of the specimen was controlled at approximately $97 \%$. Finally, the molded specimen was regenerated under constant humidity conditions. Figure 7 shows the UCS test of the specimen with 28 days of curing, which was carried out in the laboratory. Additionally, in order to analyze the subgrade packing strength under saturated water conditions, the same test was carried out in the saturated state, and the specific test results are shown in Table 2.

It can be seen from Table 3 that the UCS of the specimen under the optimal moisture content was in the range of $0.85 \mathrm{MPa}$ to $0.62 \mathrm{MPa}$, the mean value was $0.74 \mathrm{MPa}$, and the 


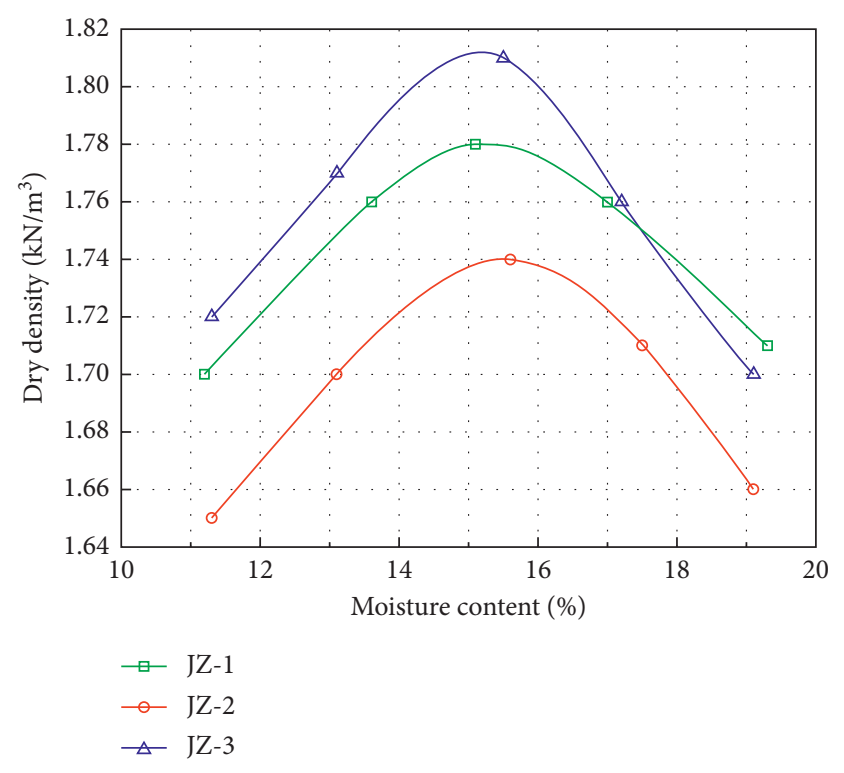

FIGURE 5: Relationship between moisture content and dry density for the C\&D waste.

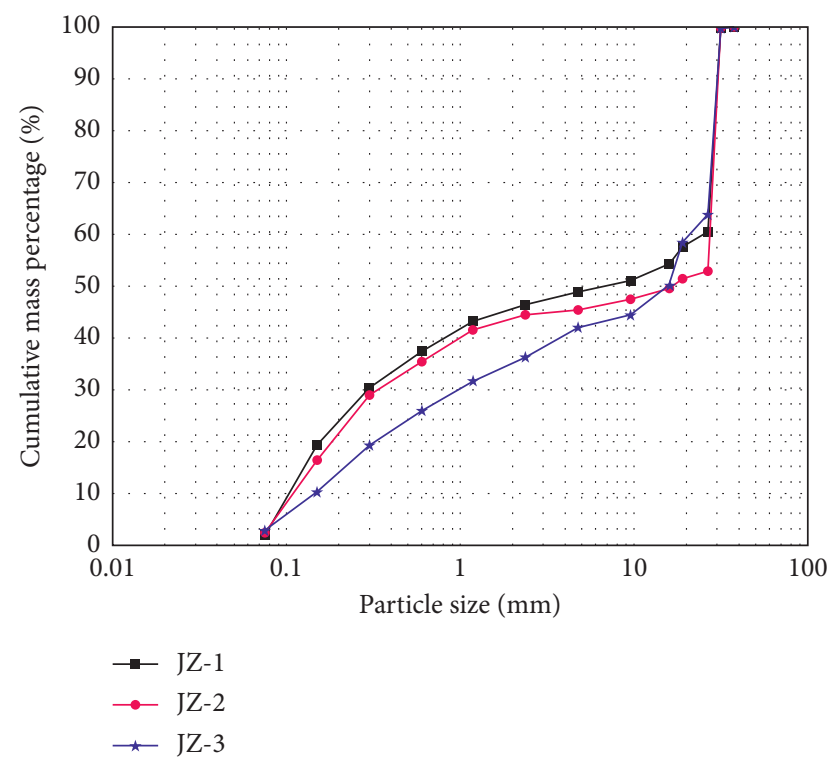

Figure 6: Particle size distribution of C\&D waste after compaction.

range was $0.23 \mathrm{MPa}$. Under the condition of saturated water, the UCS was in the range of 0.62 to $0.39 \mathrm{MPa}$, the mean value was $0.53 \mathrm{MPa}$, and the range was $0.25 \mathrm{MPa}$. Under the condition of optimal moisture content, the UCS of the filler was about 1.4 times that which occurred in the saturated state. From the experimental results, water content has a definite impact on the strength of the filler. According to requirements of the specifications, the minimum strength in the saturated state can also meet the requirements of the road. The feasibility of the C\&D waste for use as an embankment filler is verified.

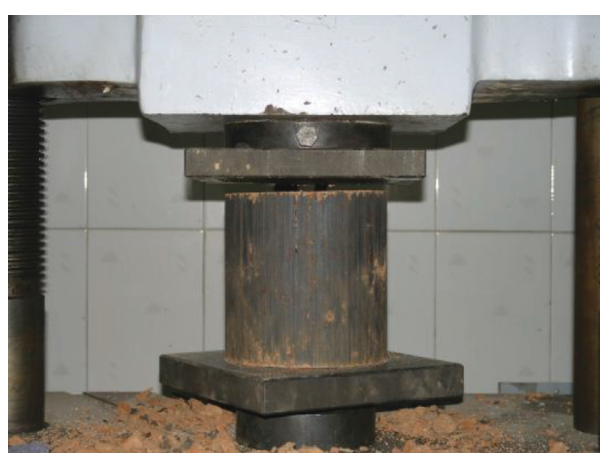

Figure 7: UCS test in the laboratory.

3.4. CBR Test. The CBR test is a widely used and adaptable penetration testing method for engineering materials [44]. In this paper, CBR tests were performed for these embankment filling materials after they were compacted. The compaction test was divided into three layers, and the specimen was compacted 98 times in every layer. The CBR test was conducted after the specimens had been soaked in water for four days. The test results are summarized in Table 3. It can be seen that when penetration is $2.5 \mathrm{~mm}$, the CBR values of specimens 1,2 , and 3 are $38.6 \%, 24.1 \%$, and $41.4 \%$, respectively. The average value is $34.7 \%$, while the penetration is $5.0 \mathrm{~mm}$, and the average value of the sample is $43.0 \%$. Thus, the C\&D waste strength stuffing meets the requirement of specification (JTG D30-2004) [45].

\section{Field Compaction Test}

Strict control of subgrade compaction is an important guarantee to improve the overall strength and stability of the subgrade. The compaction function should be controlled within a reasonable range, which is necessary to ensure adequate compaction and avoid the excessive exertion of compaction energy to ensure that the particle size does not become too small to achieve continuous grading or prevent the final compaction degree of packing from meeting the requirements [46-49]. In the field compaction process, after a period of curing time to bring the composite material to moderate moisture content, a spiky roller was used for compaction. The rolling occurs along the two sides and then to the middle, and the rolling speed is controlled at approximately $3 \mathrm{~km} / \mathrm{h}$. The wheel overlap is $0.4-0.5 \mathrm{~m}$. When the waste has been rolled 10 times, the particle size was larger according to visual inspection, as shown in Figure 8(a). When the waste has been rolled 18 times, the construction waste particle diameter was less than $3 \mathrm{~cm}$, as shown in Figure 8(b). A small amount of noncrushed reinforced concrete blocks was identified, and it was flat wheel rolled two times, which means that embankment filling was rolled a total of 20 times (Figure 8(c)).

4.1. Field Compaction and Sieve Test. The second to the fifth layer of the rolled aggregate was used for the screening test, and each layer of filler came from the material that had been rolled between 10 and 18 times. The test results are shown in 
TABLE 2: The results of UCS test.

\begin{tabular}{|c|c|c|c|c|c|c|c|c|}
\hline \multirow{2}{*}{ Optimal moisture content conditions } & Maximum pressure $(\mathrm{P})$ & $\mathrm{kN}$ & 15.0 & 11.0 & 13.0 & 13.5 & 12.5 & 13.5 \\
\hline & $\operatorname{UCS}(\mathrm{Rc})$ & $\mathrm{MPa}$ & 0.85 & 0.62 & 0.74 & 0.76 & 0.71 & 0.76 \\
\hline \multirow{2}{*}{ Saturated conditions } & Maximum pressure $(\mathrm{P})$ & $\mathrm{kN}$ & 10.9 & 9.7 & 10.1 & 8.9 & 9.4 & 8.7 \\
\hline & $\mathrm{UCS}(\mathrm{Rc})$ & $\mathrm{MPa}$ & 0.62 & 0.55 & 0.58 & 0.50 & 0.53 & 0.39 \\
\hline
\end{tabular}

TABLE 3: CBR test results of C\&D waste.

\begin{tabular}{lcccc}
\hline Penetration $(\mathrm{mm})$ & CBR (\%) & Sample 3 & Average value (\%) \\
\hline 2.5 & Sample 1 & Sample 2 & 41.4 & 34.7 \\
5.0 & 38.6 & 24.1 & 44.0 & 43.0 \\
\hline
\end{tabular}

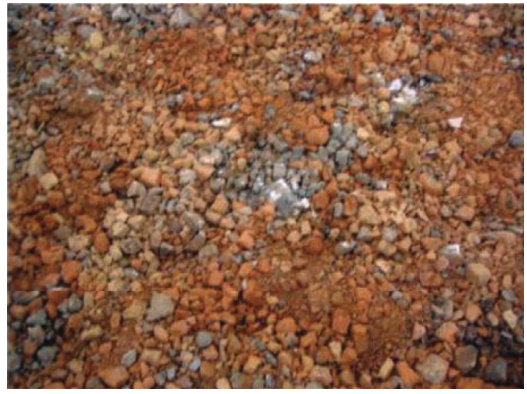

(a)

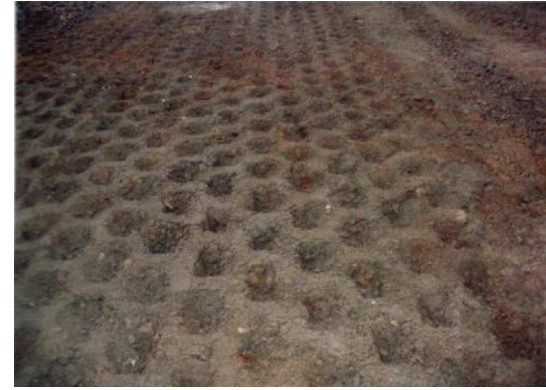

(b)

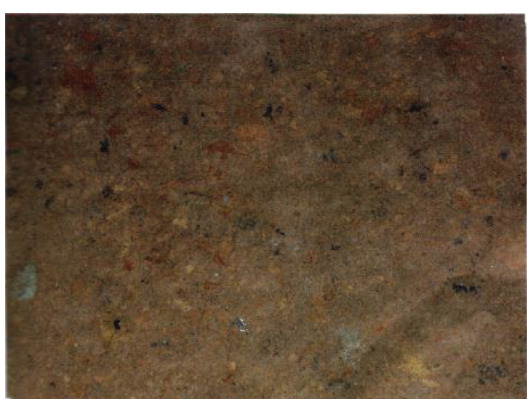

(c)

FIGURE 8: The change of subgrade test section after rolling. (a) 10 times, (b) 18 times, and (c) 20 times.

Figure 9. It can be seen that the composition of the four layers of packing at different rolling times was basically the same, the particle size is $0.07-4 \mathrm{~mm}$, and the gradation curve is consistent, indicating that the percentage of various particle size fractions was similar. Additionally, the C\&D waste in the vibration rolling process contained broken particles. As the number of rolling increased, the gradation curve gradually became steeper, and the grain diameter distribution became more uniform, especially when the number of rolling reached 18 times. At that point, $K_{w}$ increased to 1.1-1.3, indicating that the content of fine materials in the C\&D waste had increased, and the road performance was improved.

\subsection{Relation between Particle Composition and Compaction} of C\&D Waste. Figure 10 presents the relationship between the compaction degree and the particle composition of the C\&D waste. When the compaction degree was lower than $88 \%$, that is, under the action of the existing mechanical equipment, and the number of rolling times was less than 13 times, the change in the grain composition of the C\&D waste was not significant. When the compaction degree reached $88 \%$, with the increase in rolling times, the composition of the particles changed, the coarse aggregate was crushed, and the content of the fine material was notably increased. The main reasons for the above phenomenon are as follows. Firstly, when the compaction degree is small, the pore size of the C\&D waste filler itself is relatively large, and the compression of the filler is caused by the decrease in the pore volume, the crushing and failure of the granule itself is not apparent. Furthermore, when the compaction degree is large, the contact between particles becomes closer as the number of mechanical rolling increases, and the filler in the coarse aggregate is gradually broken down.

4.3. The Law of Variation of $K_{w}$ with Rolling Times and Compaction Degree. Figure 11 illustrates the variation of $K_{w}$ with the increase in rolling times during the process of the compaction of the second to the fifth layer of packing. When the number of rolling was less than 13 times, the change in the mass ratio $\left(K_{w}\right)$ of fine to coarse aggregate was less pronounced. However, when the number of rolling was more than 13 times, $K_{w}$ increased obviously. As mentioned above, the main reason is that when the material is rolled merely a few times, deformation of the filler is mainly a result of the reduction in the porosity ratio. When the number of rolling increases, the filler particles come into closer contact with each other, which ultimately increases the content of fine aggregate in the filler and improves the structure of the filler. Nevertheless, after the material was rolled for 18 times, the rate of increase of fine content in the filler was significantly reduced, and the granular composition of the filler became stable. 

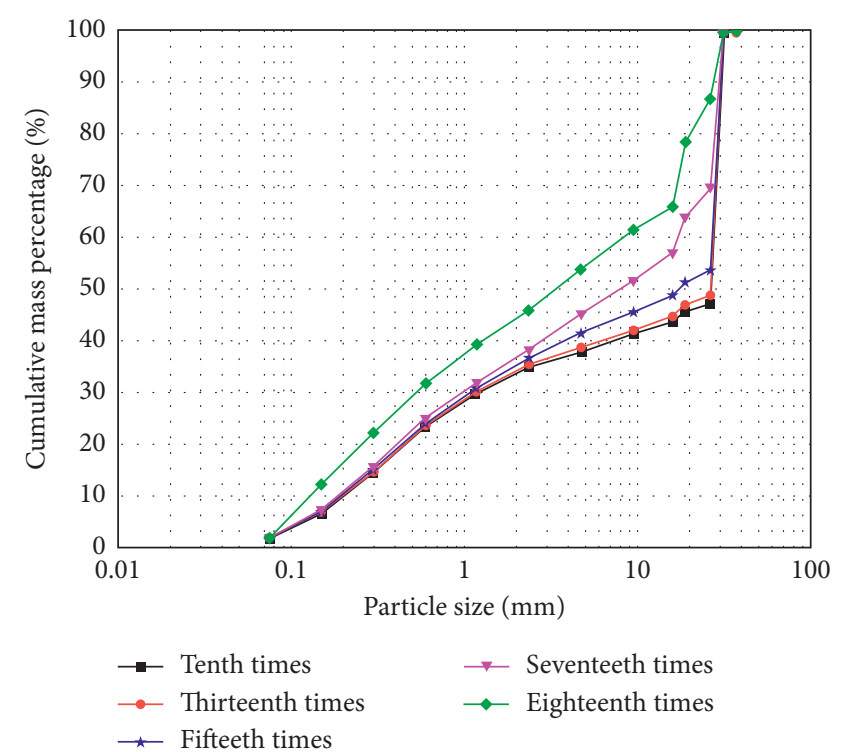

(a)
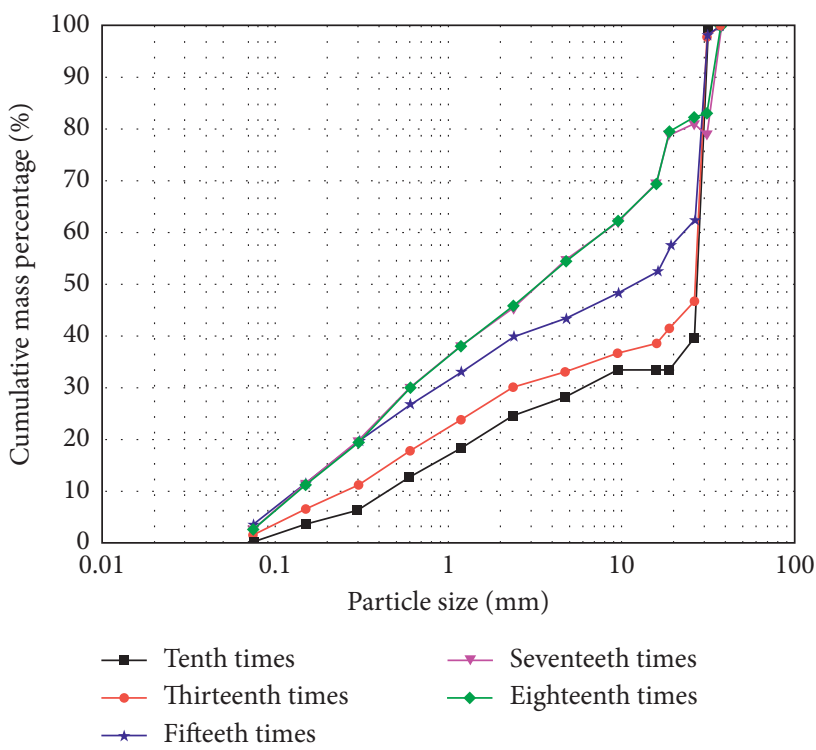

(c)

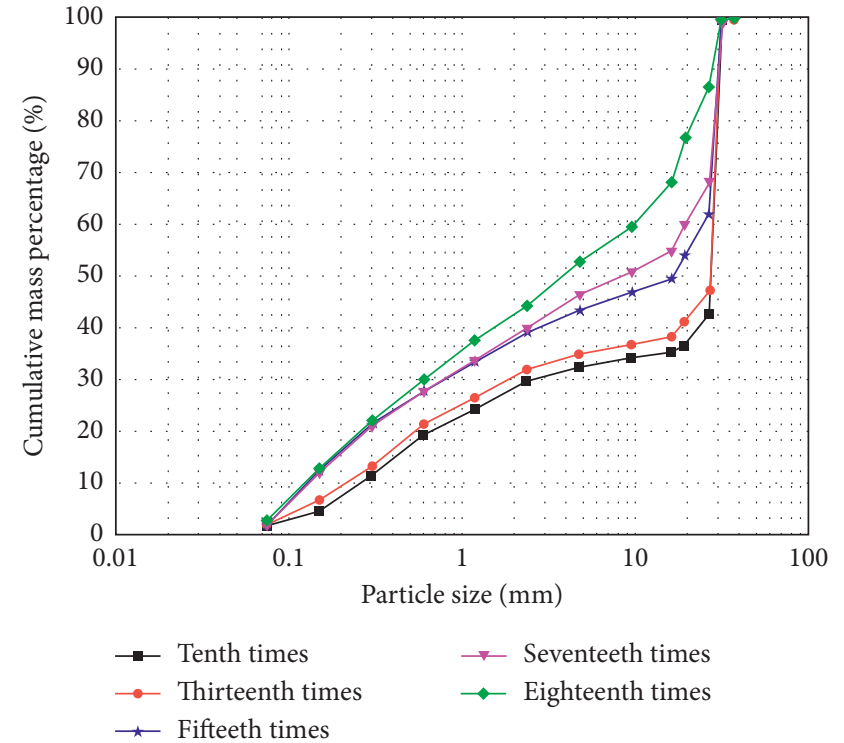

(b)

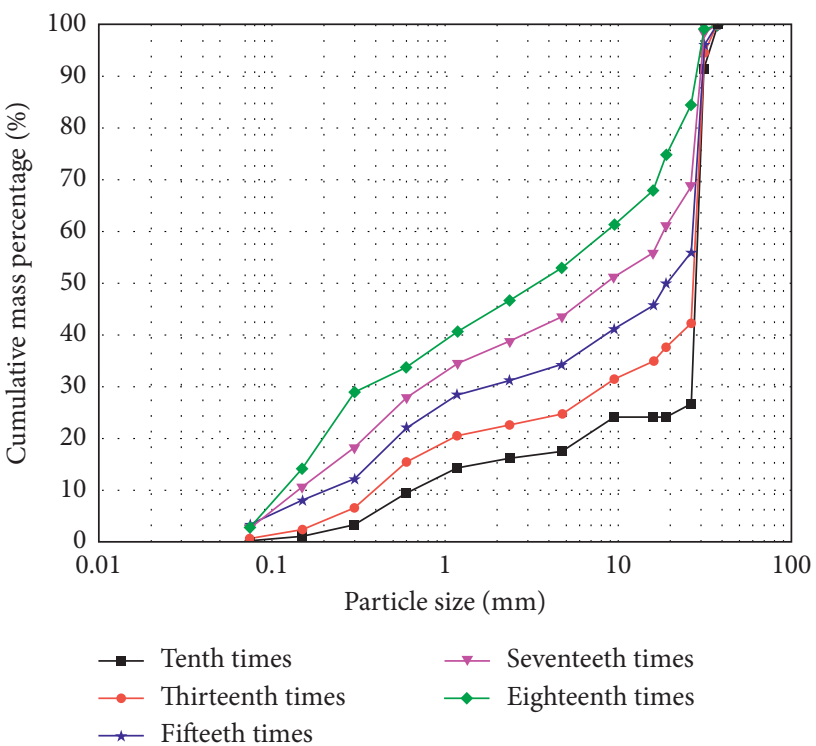

(d)

Figure 9: The gradation curve of the packing under different rolling times. (a) Second layer of filler. (b) Third layer of filler. (c) Fourth layer of filler. (d) Fifth layer of filler.

Figure 12 illustrates the variation of $K_{w}$ as the compaction degree increased. When the compaction degree is less than $88 \%$, the curve is approximately a horizontal line, indicating that the composition of filler particles in the material did not change significantly. However, when the compaction degree is higher than $88 \%$, the curve shows a clear upward trend, indicating that the content of coarse material filler decreased as the degree of compaction increased. This means that the content of the fine aggregate has been greatly increased, and the porosity ratio has been obviously decreased. At this point in the compaction process, the physical and mechanical properties of the filler have been improved. Therefore, we can conclude from the above analysis that the optimal number of rolling times is approximately 18 .

4.4. Subgrade Compaction Results and Analysis. The compaction degree is mainly relevant to the moisture content, depth of loose layers, number of rolling times, and various mechanical properties. In this study, three main parameters were selected for analysis-moisture content, depth of loose layers, and number of rolling times-to determine the extent of influence of each one on the degree of compaction. The method for measuring the compaction degree of the site was the sand cone method, as shown in Figure 13. 


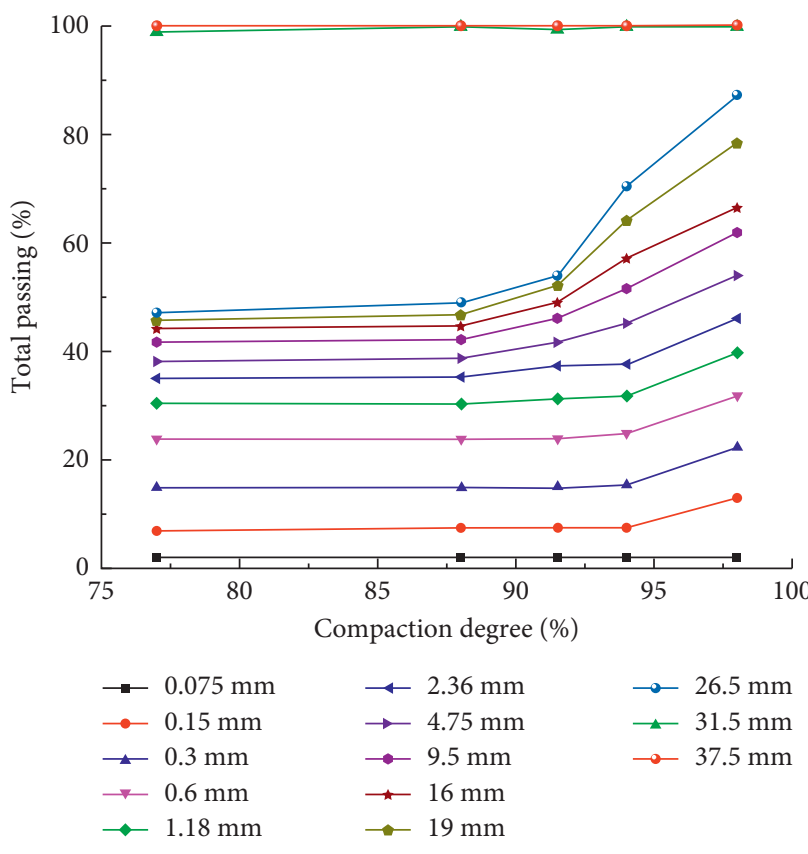

(a)

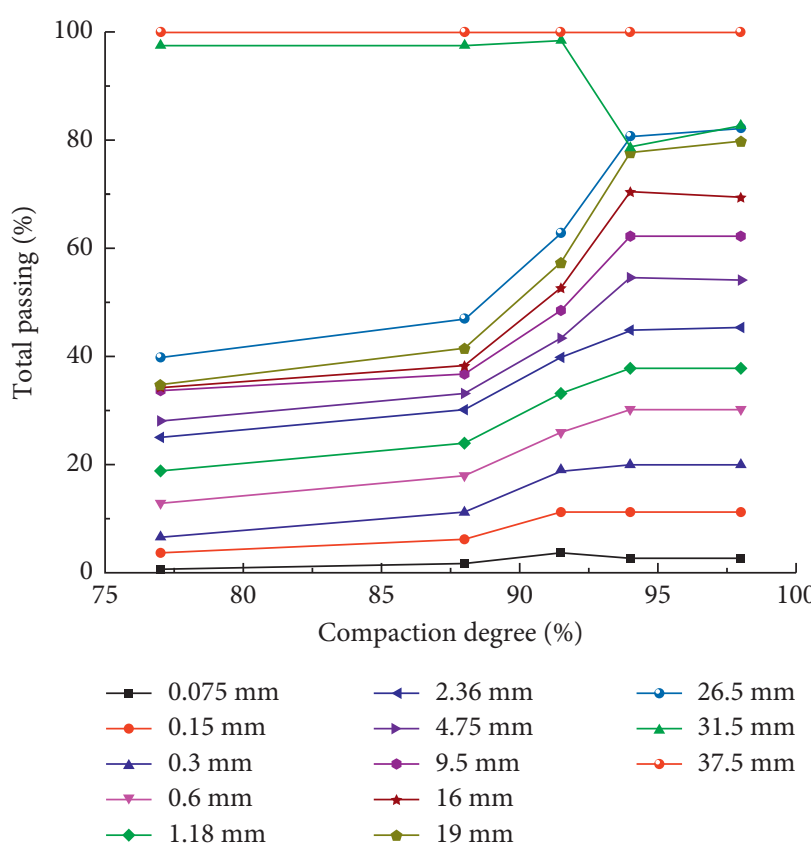

(c)

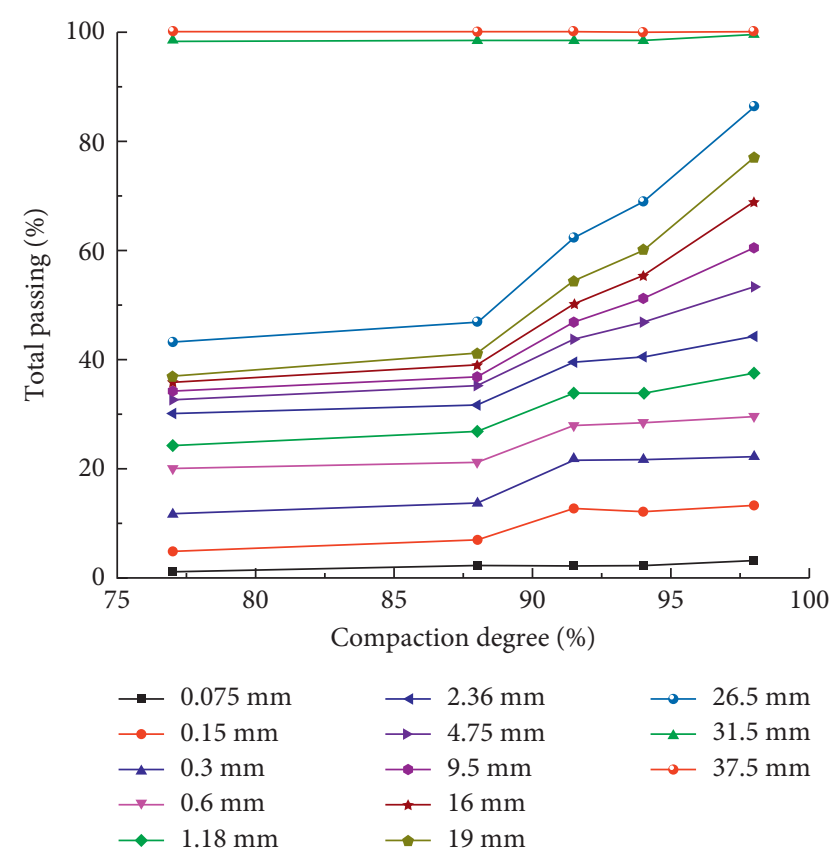

(b)

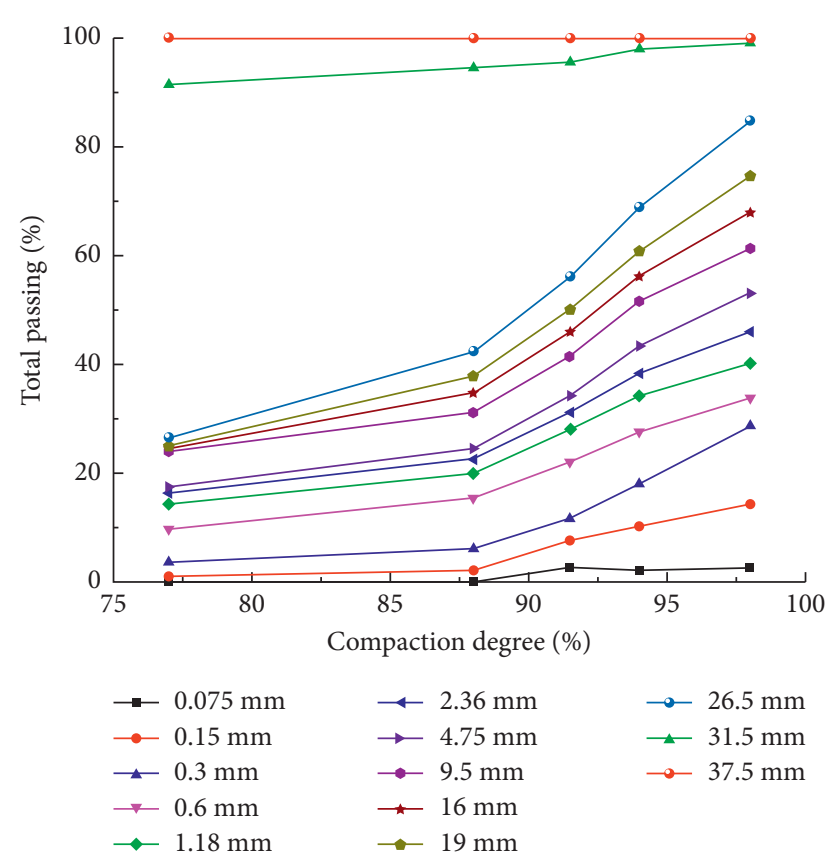

(d)

FIGURE 10: Variation of particle composition of each layer with different compaction degrees. (a) Second layer of filler. (b) Third layer of filler. (c) Fourth layer of filler. (d) Fifth layer of filler.

4.4.1. Compaction Degree-Moisture Content Relationship. The relationship between the compaction degree and the change in moisture content is shown in Figure 14. It can be seen that when the moisture content was low, because of the large degree of friction between particles, the compaction degree was also low. When the moisture content was in the range of $14.8 \%$ to $16 \%$, the compaction degree of the filling material varied from $97 \%$ to $99 \%$, indicating that the optimum moisture content of field fillers is $14.8 \%$ to $16 \%$, which also confirmed the correctness of laboratory experiment. When the water content was high, the partial compaction work was consumed due to the pore water, and the compaction effect was also not obvious. 


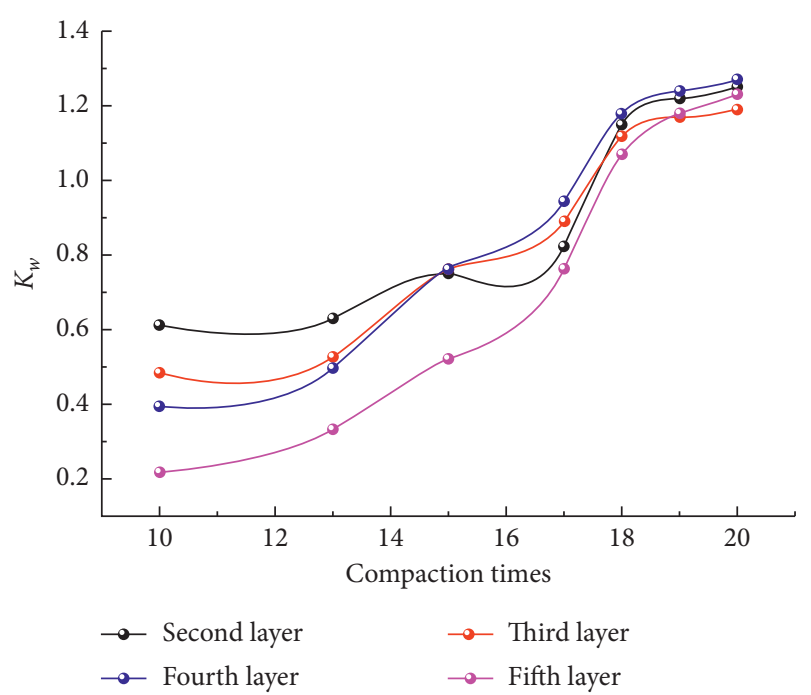

FIGURE 11: Relationship between $K_{w}$ and the number of rollings.

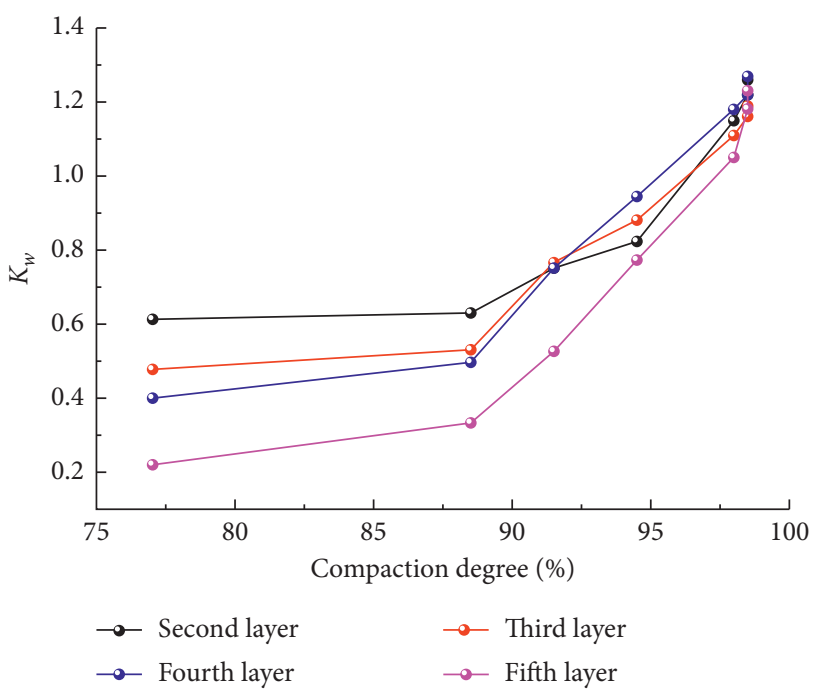

Figure 12: Relationship between $K_{w}$ and compaction degree.

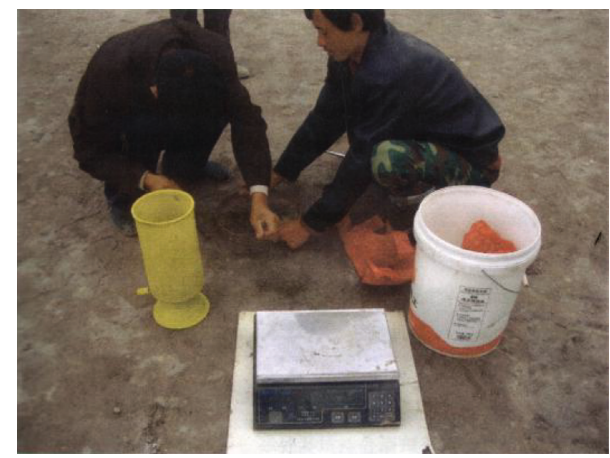

FIGURE 13: Sand cone method test.

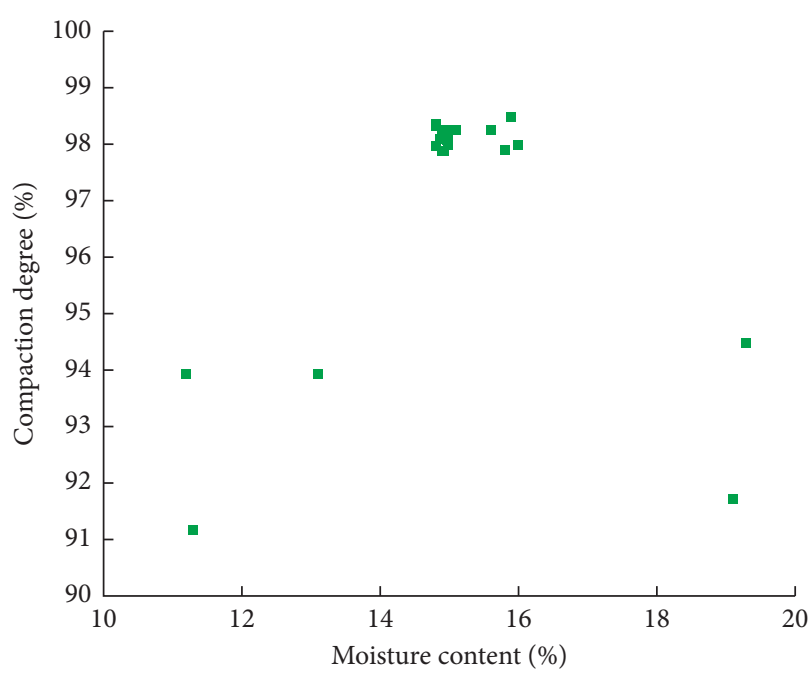

FIGURE 14: Relationship between compaction degree and water content.

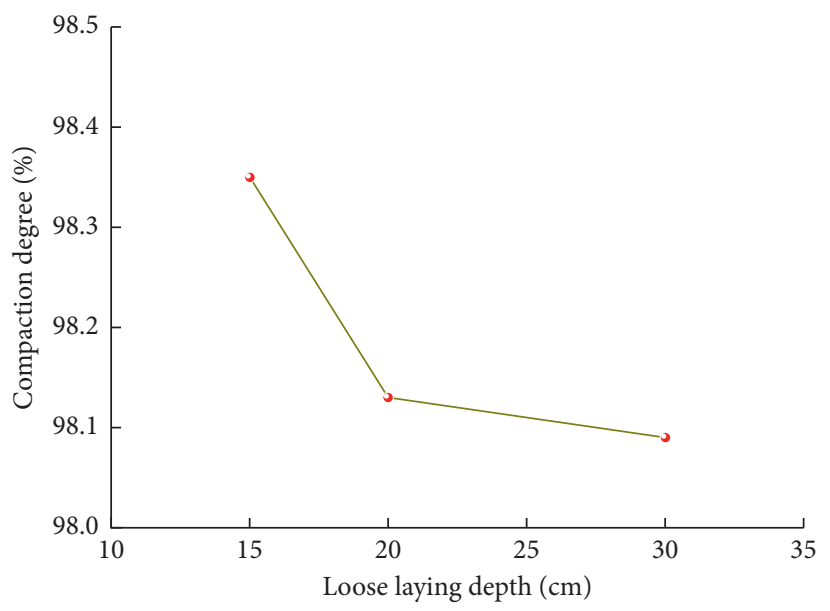

Figure 15: Relationship between compaction degree and loose laying depth.

4.4.2. Compaction Degree-Loose Laying Depth Relationship. Figure 15 shows the relationship between the compaction degree and the depth of the loose layers. Compaction degree of the filling material decreased as the thickness of the loose layers increased, according to rolling 20 times using the existing mechanical equipment. This likely occurred since the decay rate of the compaction work along the depth direction was significant, preventing the lower layers of soil from achieving the best compaction. Specifically, while the degree of compaction was reduced, it still met the requirements of the specifications. Taking into account economic factors, the condition of the existing compaction machinery, and the number of times the compaction was conducted, we found that the most economical compaction that would meet the requirements of the constructions controls was a thickness in the loose layers of $20 \mathrm{~cm}$. 


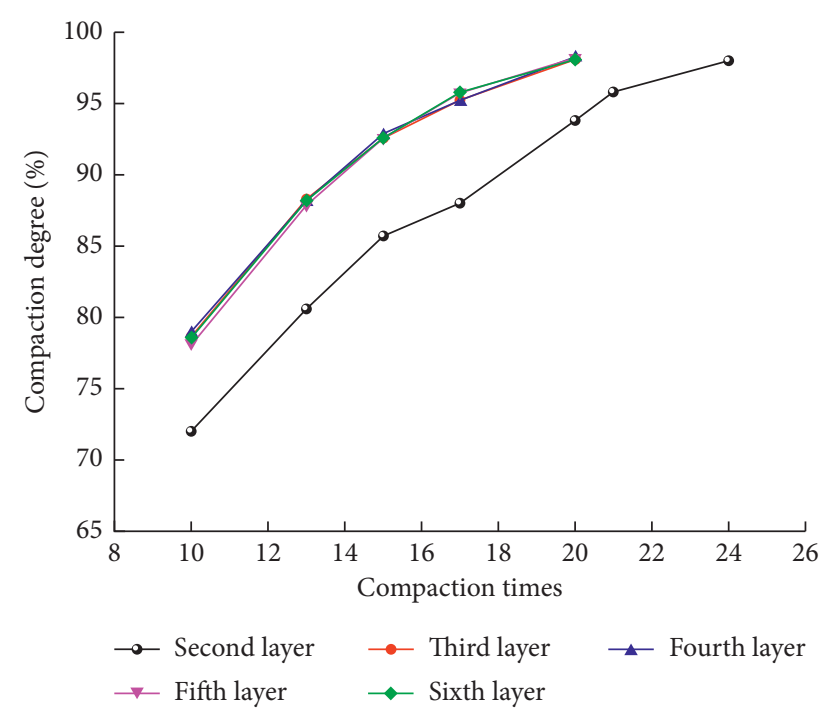

FIGURE 16: Relationship between compaction degree and rolling times.

\subsubsection{Compaction Degree-Rolling Times Relationship.} Figure 16 presents the relationship between the degree of compaction and the number of rolling times in the test section. The thickness of the second layer of the filler is $30 \mathrm{~cm}$, when rolled between 15 and 17 times, the degree of compaction was still small, and its mechanical power was relatively weak, and the compaction effect was not significant. Not until the sample was rolled 24 times were the compaction requirements achieved. Therefore, we find that this method is inefficient and cannot guide the construction. The compaction degree of the filler of packing layers 3 to 6 for the same number of rolling was basically the same. In the early stage of rolling, the dry density of the filler increased rapidly. For example, when rolled approximately 10 times, the compaction degree of the packing was approximately $78.5 \%$. When rolled 13 times, the compaction degree of the packing increased to $88 \%$; nevertheless, with the number of rolling continued to increase beyond that, the increase in the degree of compaction declined. When the number of rolling reached 20, the filler had a compaction degree of $97 \%$ or more. When the number of rolling is greater than 20 times, there was no significant switch in compaction. In actual construction conditions, the intervals and compaction degree requirements are different, when the degree of compaction is $93 \%$, the specifications can be gratified, and the number of rolling at this time can be set to 15 times. If the degree of compaction requirement is $95 \%$, subsequently the number of rolling may be set to 17 times. Therefore, in the case of the compaction machine, the reasonable control of the number of rolling has an important engineering significance.

4.5. Analysis of Field Deflection and Resilient Modulus. The deflection and resilient modulus are an important index of the subgrade quality evaluation [50-54]. Therefore, a field deflection test was carried out after the final packing of each layer of the embankment, and the

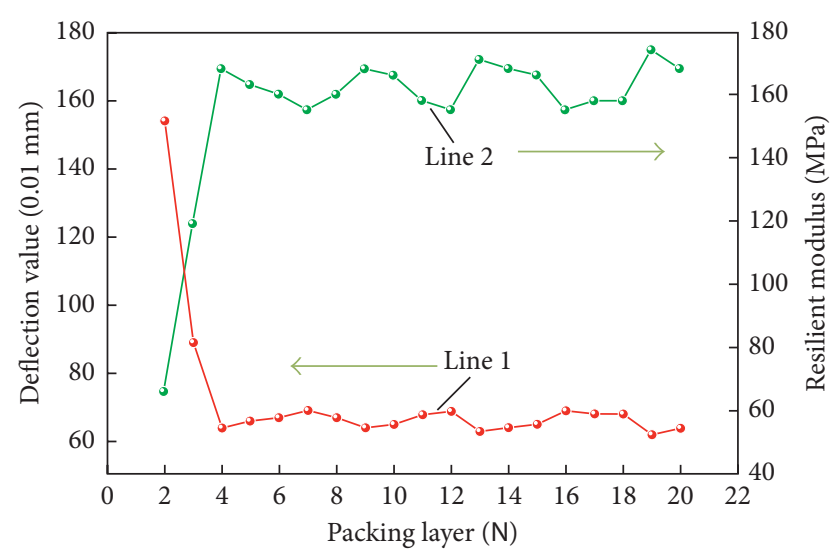

Figure 17: Deflection and resilient modulus of subgrade.

resilient modulus was obtained using the deflection value obtained from the field deflection test. The empirical formula of the subgrade resilient modulus and deflection value is as follows [55]:

$$
E_{0}^{\prime}=K_{1} E_{0},
$$

where $E_{0}^{\prime}$ is the nonnegative seasonal rebound modulus (MPa), $E_{0}$ is the resilient modulus ( $\left.\mathrm{MPa}\right)$, and $K_{1}$ is the seasonal influence coefficient (this study takes 1.2).

The regression equation of soil base deflection and the resilience modulus is

$$
l_{0}=9308 E_{0}^{\prime-0.938},
$$

where $l_{0}$ is the calculation value of resilient modulus on top of soil base, $0.01 \mathrm{~mm}$.

Therefore, the resilient modulus of the embankment may be estimated using the following equation:

$$
E_{0}=\frac{\sqrt[0.938]{9380 / l_{0}}}{K_{1}} .
$$

Figure 17 presents the results of the field deflection and resilient modulus test for the second through the twentieth layer. Except for the first and second layer fillings (the results for which were altered by the change in the thickness of the test), the deflection value was found to be large, and the resilient modulus value was low. The thickness of the other layers was $20 \mathrm{~cm}$, the deflection value of the test fell mainly between 0.6 and $0.7 \mathrm{~mm}$ with an average was $0.66 \mathrm{~mm}$, the coefficient of variation was 0.036 , and the standard deviation was 8.19. The resilient modulus was mainly between 155 and $174 \mathrm{MPa}$ with an average of $162.69 \mathrm{MPa}$, the coefficient of variation was 0.038 , the standard deviation was 6.12 , and the deflection value and resilient modulus were stable in the construction of each test section. Additionally, taking into account the fact that current research on the applications of C\&D waste as an embankment filler is relatively sparse, there is no relevant standards for reference. Compared with resilient modulus of the gravel packing, it meets the requirements of subgrade construction. 


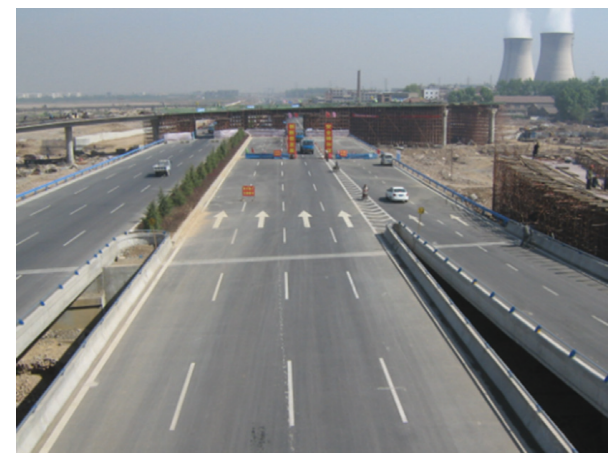

FIgure 18: Completed east Sanhuan road.

\section{Conclusions}

(1) Results from laboratory test and field rolling test demonstrated that the effect of compaction was best when the moisture content of C\&D waste was controlled at $15 \%-16 \%$ and the quality ratio of fine materials and coarse materials of $C \& D$ waste was 0.328 and 1.1-1.2 before and after rolling, respectively. It indicates that the content of fine material is greatly increased after simple treatment, and the road performance is improved.

(2) The UCS of the specimen under the optimal moisture content was in the range of $0.85 \mathrm{MPa}$ to $0.62 \mathrm{MPa}$, and the mean value was $0.74 \mathrm{MPa}$. The average CBR value of specimens was at least $34.7 \%$, which met the requirements for subgrade filling, respectively.

(3) With the increase in the number of rolling times, the compaction degree of the embankment filler increased gradually, and the compaction rate increased in the initial stages, while decreasing gradually in the later stages. Under the condition that the thickness of the loose layer is $20 \mathrm{~cm}$, the compaction times are suggested to be controlled 15-20 times, which can meet the requirement of compaction.

(4) The field deflection test showed that the average deflection of the embankment was $0.66 \mathrm{~mm}$, and the resilient modulus was $162.7 \mathrm{MPa}$, which meets the requirements of relevant specifications. It demonstrates that the construction of subgrade filled with $\mathrm{C} \& \mathrm{D}$ waste is feasible. At present, this project has been put into operation (Figure 18) and has saved construction costs and reduced land use and potential environmental impacts.

\section{Conflicts of Interest}

The authors declare that there are no conflicts of interest regarding the publication of this paper.

\section{Acknowledgments}

This work is financially supported by the Western Traffic Science and Technology Project (Grant no. 2014318 J27 210) and the Special Fund for Basic Scientific Research of Central Colleges of Chang'an University (Grant nos. 310821172004, 310821165011, and 310821153312).

\section{References}

[1] H. Yuan and L. Shen, "Trend of the research on construction and demolition waste management," Waste Management, vol. 31, no. 4, pp. 670-679, 2011.

[2] L. Zheng, H. Y. Wu, H. Zhang et al., "Characterizing the generation and flows of construction and demolition waste in china," Construction and Building Materials, vol. 136, pp. 405-413, 2017.

[3] M. Erlandsson and P. Levin, "Environmental assessment of rebuilding and possible performance improvements effect on a national scale," Building and Environment, vol. 40, no. 11, pp. 1459-1471, 2005.

[4] G. Banias, C. Achillas, C. Vlachokostas, N. Moussiopoulos, and S. Tarsenis, "Assessing multiple criteria for the optimal location of a construction and demolition waste management facility," Building and Environment, vol. 45, no. 10, pp. 2317-2326, 2010.

[5] H. Duan, J. Wang, and Q. Huang, "Encouraging the environmentally sound management of C\&D waste in china: an integrative review and research agenda," Renewable and Sustainable Energy Reviews, vol. 43, pp. 611-620, 2015.

[6] C. S. Poon, A. T. W. Yu, and L. Jaillon, "Reducing building waste at construction sites in Hong Kong," Construction Management and Economics, vol. 22, no. 5, pp. 461-470, 2004.

[7] J. L. Qiu, X. L. Wang, S. Y. He, H. Liu, J. Lai, and L. Wang, "The catastrophic landside in Maoxian County, Sichuan, SW China on June 24, 2017," Natural Hazards, 2017.

[8] J. X. Lai, S. Y. He, J. L. Qiu et al., "Characteristics of earthquake disasters and aseismic measures of tunnels in Wenchuan earthquake," Environmental Earth Sciences, vol. 76, no. 2, p. 94, 2017.

[9] J. X. Lai, J. L. Qiu, H. B. Fan, J. Chen, and Y. Xie, "Freeze-proof method and test verification of a cold region tunnel employing electric heat tracing," Tunnelling and Underground Space Technology, vol. 60, pp. 56-65, 2016.

[10] B. Melbouci, "Compaction and shearing behaviour study of recycled aggregates," Construction and Building Materials, vol. 23, no. 8, pp. 2723-2730, 2009.

[11] A. Arulrajah, J. Piratheepan, M. Disfani, and M. W. Bo, "Geotechnical and geoenvironmental properties of recycled construction and demolition materials in pavement subbase applications," Journal of Materials in Civil Engineering, vol. 25, no. 8, pp. 1077-1088, 2013.

[12] A. Jamshidi, K. Kurumisawa, T. Nawa, and T. Igarashi, "Performance of pavements incorporating waste glass: the current state of the art," Renewable and Sustainable Energy Reviews, vol. 64, pp. 211-236, 2016.

[13] H. N. Wang, Z. P. You, J. Mills-Beale, and P. Hao, "Laboratory evaluation on high temperature viscosity and low temperature stiffness of asphalt binder with high percent scrap tire rubber," Construction and Building Materials, vol. 26, no. 1, pp. 583590, 2012.

[14] M. Fakhri and S. K. Farshad, "The effect of waste rubber particles and silica fume on the mechanical properties of roller compacted concrete pavement," Journal of Cleaner Production, vol. 129, pp. 521-530, 2016.

[15] H. N. Wang, R. Zhang, Y. Chen, Z. You, and J. Fang, "Study on microstructure of rubberized recycled hot mix asphalt 
based X-ray CT technology," Construction and Building Materials, vol. 121, pp. 177-184, 2016.

[16] J. X. Lai, H. Q. Liu, J. L. Qiu, and J. Chen, "Settlement analysis of saturated tailings dam treated by CFG pile composite foundation," Advances in Materials Science and Engineering, vol. 2016, Article ID 7383762, 10 pages, 2016.

[17] J. X. Lai, S. Mao, J. L. Qiu et al., "Investigation progresses and applications of fractional derivative model in geotechnical engineering," Mathematical Problems in Engineering, vol. 2016, Article ID 9183296, 15 pages, 2016.

[18] L. A. D. C. Bastos, G. C. Silva, J. C. Mendes, and R. A. F. Peixoto, "Using iron ore tailings from tailing dams as road material," Journal of Materials in Civil Engineering, vol. 28, no. 10, p. 04016102, 2016.

[19] F. Maghool, A. Arulrajah, S. Horpibulsuk, and Y.-J. Du, "Laboratory evaluation of ladle furnace slag in unbound pavement-base/subbase applications," Journal of Materials in Civil Engineering, vol. 29, no. 2, p. 04016197, 2016.

[20] L. L. Ekanayake and G. Ofori, "Building waste assessment score: design-based tool," Building and Environment, vol. 39, no. 7, pp. 851-861, 2004.

[21] K. Sobhan and R. J. Krizek, "Fatigue behavior of fiberreinforced recycled aggregate base course," Journal of Materials in Civil Engineering, vol. 11, no. 2, pp. 124-130, 1999.

[22] T. Park, "Application of construction and building debris as base and subbase materials in rigid pavement," Journal of Transportation Engineering, vol. 129, no. 5, pp. 558-563, 2003.

[23] S. P. Chi and D. Chan, "Feasible use of recycled concrete aggregates and crushed clay brick as unbound road sub-base," Construction and Building Materials, vol. 20, no. 8, pp. 578585, 2006.

[24] V. Ayan, M. C. Limbachiya, J. R. Omer, and S. M. N. Azadani, "Compaction assessment of recycled aggregates for use in unbound subbase application," Journal of Civil Engineering and Management, vol. 20, no. 2, pp. 169-174, 2014.

[25] D. X. Xuan, A. A. A. Molenaar, and L. J. M. Houben, "Evaluation of cement treatment of reclaimed construction and demolition waste as road bases," Journal of Cleaner Production, vol. 100, pp. 77-83, 2015.

[26] A. R. Pasandín and I. Pérez, "Mechanical properties of hotmix asphalt made with recycled concrete aggregates coated with bitumen emulsion," Construction and Building Materials, vol. 55, pp. 350-358, 2014.

[27] J. Zhu, S. Wu, J. Zhong, and D. Wang, "Investigation of asphalt mixture containing demolition waste obtained from earthquake-damaged buildings," Construction and Building Materials, vol. 29, no. 4, pp. 466-475, 2012.

[28] B. Gómez-Meijide and I. Pérez, "Effects of the use of construction and demolition waste aggregates in cold asphalt mixtures," Construction and Building Materials, vol. 51, no. 51, pp. 267-277, 2014.

[29] B. Gómez-Meijide, I. Pérez, and A. R. Pasandín, "Recycled construction and demolition waste in cold asphalt mixtures: evolutionary properties," Journal of Cleaner Production, vol. 112, pp. 588-598, 2016.

[30] J. X. Lai, J. L. Qiu, H. B. Fan et al., "Fiber bragg grating sensors-based in-situ monitoring and safety assessment of loess tunnel," Journal of Sensors, vol. 2016, Article ID 8658290 , 10 pages, 2016.

[31] J. X. Lai, H. B. Fan, J. X. Chen, J. Qiu, and K. Wang, "Blasting vibration monitoring of undercrossing railway tunnel using wireless sensor network," International Journal of
Distributed Sensor Networks, vol. 2015, Article ID 703980, 7 pages, 2015.

[32] N. Cristelo, C. S. Vieira, and M. D. L. Lopes, "Geotechnical and geoenvironmental assessment of recycled construction and demolition waste for road embankments," Procedia Engineering, vol. 143, pp. 51-58, 2016.

[33] R. M. Brooks and M. Cetin, "Application of construction demolition waste for improving performance of subgrade and subbase layers," International Journal of Research and Reviews in Applied Sciences, vol. 12, no. 3, p. 375, 2012.

[34] J. X. Lai, K. Y. Wang, J. L. Qiu, F. Niu, J. Wang, and J. Chen, "Vibration response characteristics of the cross tunnel structure," Shock and Vibration, vol. 2016, Article ID 9524206, 16 pages, 2016 .

[35] M. O. Hamzah, "Properties of geometrically cubical aggregates and its mixture design," International Journal of Research and Reviews in Applied Sciences, vol. 3, no. 3, 2010.

[36] J. Mills-Beale and Z. P. You, "The mechanical properties of asphalt mixtures with recycled concrete aggregates," Construction and Building Materials, vol. 24, no. 3, pp. 230235, 2010.

[37] A. Diab and Z. P. You, "Development of a realistic conditioning and evaluation system to study moisture damage of asphalt materials," Airfield and Highway Pavement Conference, pp. 1008-1017, 2013.

[38] W. H. Zhou, H. Y. Qin, J. L. Qiu et al., "Building information modelling review with potential applications in tunnel engineering of China," Royal Society Open Science, vol. 4, no. 8, p. 170174, 2017.

[39] A. Arulrajah, M. M. Y. Ali, J. Piratheepan, and M. W. Bo, "Geotechnical properties of waste excavation rock in pavement subbase applications," Journal of Materials in Civil Engineering, vol. 24, no. 7, pp. 924-932, 2012.

[40] Z. P. You and Q. L. Dai, "Review of advances in micromechanical modeling of aggregate-aggregate," Canadian Journal of Civil Engineering, vol. 34, no. 2, pp. 239-252, 2007.

[41] A. Q. Shen, Road Engineering Materials, China Communications Press, Beijing, China, 2010, in Chinese.

[42] A. B. R. Chini, S. S. Kuo, J. M. Armaghani, and J. P. Duxbury, "Test of recycled concrete aggregate in accelerated test track," Journal of Transportation Engineering, vol. 127, no. 6, pp. 486-492, 2001.

[43] Ministry of Transport of the People's Republic of China, Test Method of Soils for Highway Engineering (JTG E402007), China Communications Press, Beijing, China, 2007, in Chinese.

[44] Y. J. Jiang, L. N. Y. Wong, and J. L. Ren, “A numerical test method of California bearing ratio on graded crushed rocks using particle flow modeling," Journal of Traffic and Transportation Engineering, vol. 2, no. 2, pp. 107-115, 2015.

[45] China Ministry of Communications, Specifications for Design of Highway Subgrades (JTG D30-2004), China Communications Press, Beijing, China, 2004, in Chinese.

[46] M. A. Mooney and R. V. Rinehart, "Field monitoring of roller vibration during compaction of subgrade soil," Journal of Geotechnical and Geoenvironmental Engineering, vol. 133, no. 3, pp. 257-265, 2007.

[47] K. Lee, M. Prezzi, and N. Kim, "Subgrade design parameters from samples prepared with different compaction methods," Journal of Transportation Engineering, vol. 133, no. 2, pp. 82-89, 2007. 
[48] J. L. Qiu, H. Q. Liu, J. X. Lai et al., "Investigating the long term settlement of a tunnel built over improved loessial foundation soil using jet grouting technique," Journal of Performance of Constructed Facilities, 2018.

[49] J. L. Qiu, Y. L. Xie, H. B. Fan et al., "Centrifuge modelling of twin-tunnelling induced ground movements in loess strata," Arabian Journal of Geosciences, 2018.

[50] W. J. Xue and E. Weaver, "Influence of tire configuration on pavement response and predicted distress," International Journal of Pavement Engineering, vol. 16, no. 6, pp. 538-548, 2015.

[51] W. J. Xue and E. Weaver, "Pavement shear strain response to dual and wide-base tires," Transportation Research Record: Journal of the Transportation Research Board,vol. 2225, pp. 155-164, 2011.

[52] A. Arulrajah, J. Piratheepan, M. Disfani, and M. W. Bo, "Resilient moduli response of recycled construction and demolition materials in pavement subbase applications," Journal of Materials in Civil Engineering, vol. 25, no. 12, pp. 1920-1928, 2013.

[53] Y. Li, Y. Yang, H. S. Yu, and G. Roberts, "Correlations between the stress paths of a monotonic test and a cyclic test under the same initial conditions," Soil Dynamics and Earthquake Engineering, vol. 101, pp. 153-156, 2017.

[54] Z. F. Wang, S. L. Shen, Z. Y. Yin et al., "Rapid field evaluation of the strength of cement-stabilized clayey soil," Bulletin of Engineering Geology and the Environment, vol. 74, no. 3, pp. 991-999, 2015.

[55] JTJ 034-2000, Technical Specifications for Construction of Highway Roadbases, China Communications Press, Beijing, China, 2000, in Chinese. 

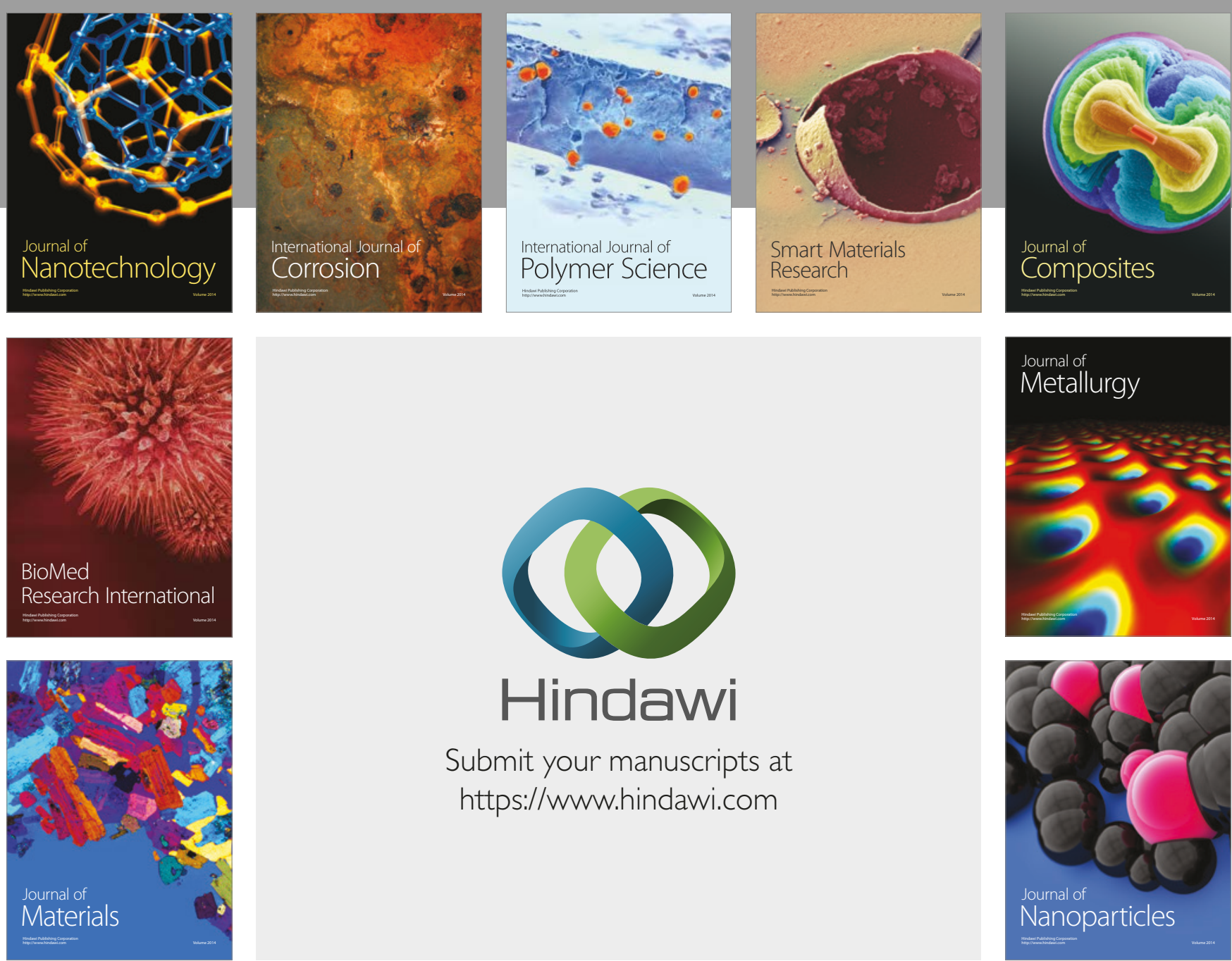

\section{Hindawi}

Submit your manuscripts at

https://www.hindawi.com
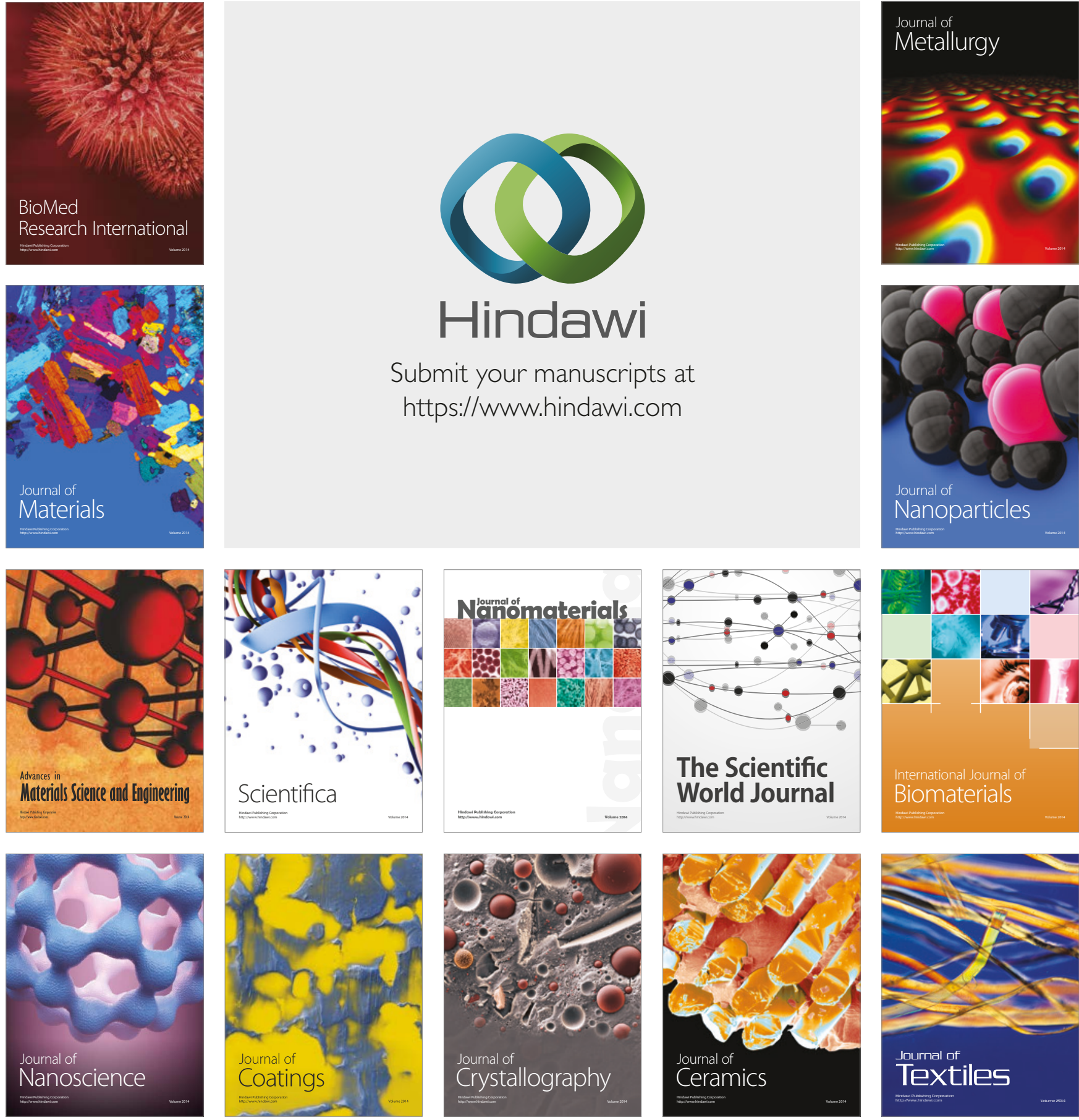

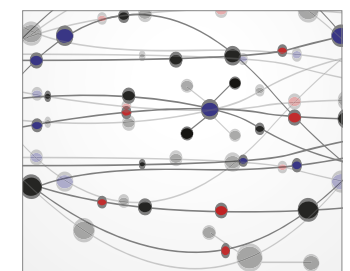

The Scientific World Journal
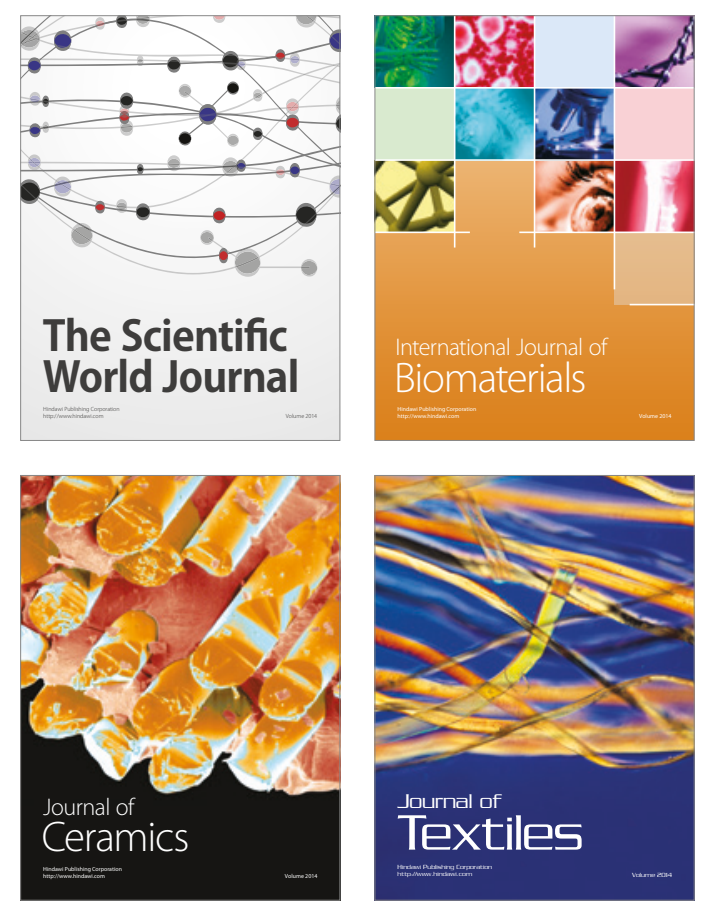